\title{
Laser-induced self-assembly of iron oxide nanostructures with controllable dimensionality.
}

\author{
Simon J. Henley* Shafikuddin Mollah†, Christina E. Giusca and S. Ravi P. Silva \\ Nano-Electronics Centre, Advanced Technology Institute, Faculty of Engineering and Physical \\ Sciences, University of Surrey, Guildford, GU2 7XH, UK
}

\begin{abstract}
The nanosecond pulsed laser ablation of a fine iron powder submerged under different liquid media (water, methanol, ethanol and isopropanol) is used to rapidly produce a variety of iron oxide nanostructures from nanoparticles to nanowires and nanosheets. The dimensionality of the nanostructres is shown to be a consequence of two controllable mechanisms. The rapid oxidation, collisional quenching and coalescence of the ablation products is suggested as the dominant mechanism for the formation of $0 \mathrm{D}$ nanostructures such as hematite $\left(\alpha-\mathrm{Fe}_{2} \mathrm{O}_{3}\right)$ nanoparticles in water, or iron oxyhydroxide nanoparticles under alcohols. By employing different laser wavelengths (248 and $532 \mathrm{~nm}$ ) it is demonstrated that the growth of extended iron oxyhydroxide nanostructures (1D nanowires and 2D nanosheets) under methanol is possible and is a consequence of a second self-assembly mechanism driven by interaction between the UV laser pulses and the ablation products.
\end{abstract}

Low dimensional iron oxide nanostructures, such as nanoparticles and nanowires are of particular industrial and academic interest, not least because of their magnetic properties. Hematite $\left(\alpha-\mathrm{Fe}_{2} \mathrm{O}_{3}\right)$ 1D nanostructures also have applications in lithium ion battery electrodes, gas sensors, field-effect transistors, and field emission cathodes. ${ }^{1-3}$ Hematite nanowires have been synthesized by many different techniques including surface oxidation, thermal oxidation and electrochemical deposition. $^{4-7}$ These are generally complex processes taking considerable time $(1.5-120 \mathrm{~h})$, needing different gas flows and high temperatures $\left(400-800^{\circ} \mathrm{C}\right)$. Also, these processes typically produce nanowires that are attached to a metallic substrate, and thus subsequent collection for device integration can be challenging. Therefore, a solution based synthesis method to collect nanowires for

*Electronic mail: s.henley@surrey.ac.uk

${ }^{\dagger}$ Present address: Department of Physics, Aligarh Muslim University, Aligarh-202002, India. 
rapid processing would be of considerable interest. Table 1 shows a comparison of time scales and process temperatures used in selected recent publications detailing iron oxide nanowire synthesis.

Rapidly after the invention of the ruby laser in the 1960s, the capability of pulsed lasers to ablate material from the surface of solids was identified. Applications for pulsed laser ablation ${ }^{8}$ (PLA) in materials processing and thin film deposition followed swiftly. Traditionally PLA and the subsequent material deposition is performed in vacuum or in dilute gaseous environments. The collisions of energetic ablated atoms with gas molecules in low-pressure gaseous environment, and any subsequent chemical reactions, has been identified a route for synthesizing multicomponent films with controllable stoichiometry. When the ambient gas pressure is increased, such that ablated species are expected to suffer multiple collisions within the reaction chamber, ${ }^{9,10}$ the medium can be considered as weakly confining. In such confining environments nanoclusters of the target material can form as the thermalised ablated atoms condense into particulates. One example of this is the generation of carbon nanoclusters by the PLA of graphite in inert gas. ${ }^{11}$

PLA of solid targets within strongly confining media such as within liquids is increasingly being viewed as an attractive method for fabricating nanoscale materials. For example, the PLA of metals under liquids has been shown to be a versatile method for producing a variety of metallic nanoparticles, particularly those of the noble metals. ${ }^{12-14}$ In strongly confining media short lived very high temperatures and pressures can be generated as the laser-induced plasma of ablated species rapidly thermalises by collisions with with the medium generating a shock wave. The generation and collapse of cavitation bubbles has also been suggested as a route for further generation of further extreme conditions. ${ }^{15}$ These transient high temperatures, high pressures and high densities are more favorable for the formation of metastable phases located well away from ambient conditions on the phase diagram. One example of this is the growth of diamond nanocrystals during the ablation of graphite under water. ${ }^{16}$

Similar to the ablation in reactive gases, PLA in liquid media offers the possibility of reacting the ablating species with the medium. The extreme non-equilibrium condition generated by the confined plasma, along with energetic collisions, can readily locally dissociate the liquid into its constituents. In this way metal oxide nanoparticles have been generated by PLA of metal targets in water. ${ }^{14,17}$ However, generally this method only produces nanocrystals, rather than higher dimensional nanostructures like nanowires. 
Reports of the formation of iron oxide nanostructures by laser ablation are rare, although synthesis by laser pyrolysis in the vapour phase is more common ${ }^{18}$ and the formation of iron oxide coatings on the surface of the laser irradiated iron targets has been observed. ${ }^{19}$ In this paper the formation of iron oxides nanostructures by laser ablation of iron powder under different liquid media is examined. By varying the liquid or by changing the irradiation time, the formation of iron oxide 0D (nanoparticles), 1D (nanowires) and 2D (nanosheets) nanostructures is achieved and the controlling mechanism are discussed.

\section{Results and Discussion}

\section{Synthesis of nanoparticles}

Iron oxide nanostructures were synthesized by a PLA technique using the pulses from a LambdaPhysik LPX 210i excimer laser operating at $248 \mathrm{~nm}$ (UV) with a pulse duration of $25 \mathrm{~ns}$ or a Nd-YAG laser operating at wavelength $532 \mathrm{~nm}$ (green) with duration $15 \mathrm{~ns}$. Iron (Fe) powder with a maximum particle size of $60 \mu \mathrm{m}$ was used as the starting material and was placed in an open glass vessel, filled with a liquid, and mounted on an X-Y translation motorised stage. A scanning electron microscope (SEM) image of the iron powder used is shown in figure 1.

In the initial experiment, water was used as the liquid and the iron powder was exposed to 24,000 pulses of the UV laser. During the process it was observed that the solution turned a faint orange color. Figure 2 shows a SEM image of the particles present in the solution after it was drop-cast onto a silicon surface and allowed to dry. Nanoparticles approximately $50 \mathrm{~nm}$ in diameter, with a relatively small size distribution were observed. Figure 3 shows the plot of the optical absorption coefficient $\alpha$ as a function of wavelength for solution formed by UV PLA of iron in water. The very small contribution to the absorption due to the water has been removed. Optical absorption is observed across the visible spectrum increasing rapidly at shorter wavelengths. If the absorption band edges are fitted to a direct transition, the optical band-gap of the nanoparticles in solution can be estimated from a plot of $(\alpha E)^{2}$ against $\mathrm{E}$, where $\mathrm{E}$ is the photon energy. Such a plot is shown in the inset of figure 3. Extrapolation of the straight portion of the curve to the energy axis gives a band-gap value $2.6 \mathrm{eV}$. The value for bulk hematite has band gap of 2-2.2 eV. However, similar large blue-shifts have been observed in the absorption spectra of hematite nanoparticles. 
For example Desai et al. measured a band-gap of $2.64 \mathrm{eV}$ for hematite quantum dots deposited by spray pyrolysis. ${ }^{20}$ Thus, we assign the hematite phase to the nanoparticles produced by PLA of iron powder in water.

A similar experiment was performed using methanol, ethanol and isopropanol as the liquids, using the same number of pulses of the UV laser. Here, the solution were observed either to remain clear and gain a faint yellow coloration, in the case of ethanol and isopropanol, or turn a cloudy yellow color when methanol was used. The optical absorption spectra of the resulting solutions are shown in figure 4 . When these alcohols are used as the liquid, the absorption spectrum was markedly different from that observed using water. Rather than extending across the visible range, the absorption is mainly limited to the UV wavelengths. In the case of methanol the measured nonzero absorption coefficient at longer wavelength is artificial, and likely a consequence of scattering of the incident light from larger nanostructures. These structures will be discussed in more detail later.

As it can be seen clearly from figure 4 significant optical absorption in the solution occurs at the laser wavelength $(248 \mathrm{~nm})$. This absorption is due to the ablation products, as all the starting liquids are effectively transparent at this wavelength. As the ablation continues this absorption increases. For this reason an iron powder, rather than a solid iron target was used. Due to the high temperatures and pressures induced at the laser focal spot, the surrounding solvent was observed to boil locally, violently ejecting iron powder away from the focal point. These ejected particles were rapidly heated by subsequent laser shots, before they settle back, a process which was observed as bright flashes of light. Even when the solution absorbs a large fraction of the laser energy, the ejection of iron particles continued, allowing the synthesis to be run for longer periods of time than would be possible with a solid iron target.

From the absorption spectra it should be possible to investigate in which oxidation state the iron ablation products assume. Results from optical absorption measurements of iron oxyhydroxide $(\mathrm{FeO}(\mathrm{OH})$ nanoparticles stabilized in solution by the presence of hydroxyl groups on carbohydrates, performed by Kudasheva et al., ${ }^{21}$ showed absorption bands in the 300-350 nm region. They attributed this band to an oxo-metal charge transfer absorption. The presence of aquated Fe(II) or hematite are both expected to produce absorption bands above 400-500 $\mathrm{nm}$. The data presented in figure 4 would be consistent with the presence of ferric oxyhydroxide complexes or nanoparticles 
for the ablation of iron in simple alcohols. The formation mechanisms for these products will be discussed in more detail later. It should be noted that the sample produced in methanol showed the strongest absorption at the 300-350 nm band, which would suggest enhanced formation of the oxide/oxyhydroxide products compared with the other alcohols.

In order to examine the nanostructure of the products formed by ablation under the alcohols, samples were dried onto silicon substrates and examined in the SEM. No significant structures were observed for ablation in ethanol or isopropanol, so any nanoparticles formed must be too small to be observed in the SEM. Ablation under methanol using the UV laser however, yielded a variety of larger nanostructures depending on the duration of the synthesis. These structures will be discussed in the next section.

\section{Synthesis of nanowires and nanosheets}

Figure 5a shows an SEM image of the products collected after 6000 shots of the UV laser onto iron powder submerged under methanol. It demonstrates lamellate "nanobelts" (widths typically 1-5 $\mu \mathrm{m}$, length $>10 \mu \mathrm{m}$, and of nanometric thickness). In addition to these $2 \mathrm{D}$ structures, nanowires (diameter 20-300 $\mathrm{nm}$, length 2-8 $\mu \mathrm{m}$ ) are also observed. When the number of shots is increased to 9000 (see figure 5(b), we again obtain nanobelts and nanowires, however the nanobelts have much larger aspect ratios, and more closely resemble the nanowires. By further increasing the number of laser shots to 24,000 , we obtain only large numbers of nanowires as shown in figure $5(\mathrm{c})$. Closer inspection of these nanowires in the transmission electron microscope (TEM), as shown in the inset of figure 5(c), one can observe that the wider wires still appear to have an asymmetric cross-section. It can also be observed that the nanowires appear amorphous, as there is no strong diffraction contrast and no evidence of crystal grains. As the morphology of the products varies with the duration of the synthesis, the typical ablation synthesis mechanism, whereby the high density of ablated species condenses to form nanoparticle, is not dominant here. This will be discussed in more detail later.

As the products appeared to be largely amorphous in nature, furnace annealing experiments were performed to crystallize the nanowires. Samples were drop-cast onto silicon wafers, the methanol allowed to evaporate, and then annealed in a furnace in air for 6-8 hours at temperatures in the range $100-800^{\circ} \mathrm{C}$. It was observed that when the annealing temperature was increased above $300^{\circ} \mathrm{C}$, 
the color of the dried products changed from yellow to rust-colored. Figure 6 shows TEM images of (a) the as grown sample, (b) the sample annealed at $400^{\circ} \mathrm{C}$ and (c) the sample annealed at $800^{\circ} \mathrm{C}$. After $400^{\circ} \mathrm{C}$ annealing the sample become nanocrystalline. By $800^{\circ} \mathrm{C}$ the nanowires are typically single crystals, but show evidence of melting as their morphology has changed.

In order to determine the crystalline structure of the annealed nanowires, the selected area electron diffraction (SAED) patterns from ensembles of nanowires were obtained. Figure 7 shows the SAED pattern for the sample annealed at $600^{\circ} \mathrm{C}$. The patterns can be fully indexed to the trigonal structure of hematite $\left(\alpha-\mathrm{Fe}_{2} \mathrm{O}_{3}\right)$. Inset in this figure is the SAED pattern of the un-annealed nanowires. The diffuse rings observed indicate that some short range order does exist.

To confirm the assignment of hematite to the annealed wires and to further investigate the un-annealed material, the Raman scattering from the nanowires was measured. Figure 8 shows the Raman spectra for the unannealed material and samples annealed at $400^{\circ} \mathrm{C}, 600^{\circ} \mathrm{C}$ and $800^{\circ} \mathrm{C}$. Peaks corresponding to $\alpha-\mathrm{Fe}_{2} \mathrm{O}_{3}$ and the silicon substrate are observed for the annealed samples. ${ }^{1,4,22,23}$ The as-prepared sample evidenced only one peak, the position of which is consistent with the most intense peak observed for the goethite structure $(\alpha-\mathrm{FeO}(\mathrm{OH})) .{ }^{22}$ However, without additional peaks, complete assignment to this stoichiometry is not possible but the yellow color of the product (goethite has been used since pre-historic times as a yellow pigment) and the fact that it was synthesized in a medium containing $\mathrm{OH}$, would support assignment as an iron oxyhydroxide.

To investigate the stoichiometry further, X-ray photoelectron spectroscopy (XPS) measurements were performed. Figure 9(a) and 9(b) show the Fe $2 p_{3 / 2}$ and Fe $2 p_{1 / 2}$ XPS spectra of the as-produced and $600{ }^{\circ} \mathrm{C}$ annealed nanowire samples, respectively. Fe $2 p_{3 / 2}$ and $\mathrm{Fe} 2 p_{1 / 2}$ peaks appear at 710.7 , $711 \mathrm{eV}$ and $724,724.5 \mathrm{eV}$ for as-produced and $600{ }^{\circ} \mathrm{C}$ annealed samples, respectively, which are close to the values ${ }^{24}$ observed for both $\alpha-\mathrm{Fe}_{2} \mathrm{O}_{3}$ and $\alpha-\mathrm{FeO}(\mathrm{OH})$. Both the position and the separation of these peaks are consistent with the presence of $\mathrm{Fe}^{3+}$ species in the samples and the formation of an iron oxyhydroxide in the as-prepared sample (Fig. 9(a)) and the $\alpha-\mathrm{Fe}_{2} \mathrm{O}_{3}$ phase in $600{ }^{\circ} \mathrm{C}$ annealed sample $^{25}$ (Fig. 9(b)). However, it has been experimentally observed that the Fe $2 p$ core levels regions show very little difference between different iron compounds or phases due to their broad and asymmetric features. This does not allow the different oxidized species to be unambiguously distinguished and their complex satellite structures complicate things further. ${ }^{25}$ Values for Fe $2 p$ binding energy in both $\alpha-\mathrm{Fe}_{2} \mathrm{O}_{3}$ and $\alpha-\mathrm{FeO}(\mathrm{OH})$ range from 710.4 to $711.5 \mathrm{eV}$, presumably due 
to the effect of the background subtraction methods and the choice of the line-shapes used for spectra analysis, as well as the effects stated above. ${ }^{26,27}$ Both spectra (Fig. 9) display the presence of relatively broad shake-up satellite peaks, which represent a well known characteristic of oxide spectra, occurring at the high binding energy side of both of the Fe $2 p$ peaks, indicating again the presence of $\mathrm{Fe}^{3+}$ species in these samples. ${ }^{27}$

To gain a clearer picture, the $\mathrm{O} 1 s$ region is investigated as shown in Fig. 10 where O $1 s$ peak can invariably be deconvoluted into two components for both the samples. O $1 s$ XPS spectra of the as-produced material and the same sample heated at $70{ }^{\circ} \mathrm{C}$ under ultra high vacuum (UHV) are shown respectively in Fig. 10(a)(i) and (ii). That of $600{ }^{\circ} \mathrm{C}$ samples is displayed in Fig. 10(b). The $70^{\circ} \mathrm{C}$ heat was performed to remove surface methanol residues. The peaks at $530.6 \mathrm{eV}$ in the as-produced sample and at $530.2 \mathrm{eV}$ in $600{ }^{\circ} \mathrm{C}$ annealed sample are due to the oxygen within the $\alpha-\mathrm{Fe}_{2} \mathrm{O}_{3}$. However, those at $532.6 \mathrm{eV}$ in as-produced sample and at $532.1 \mathrm{eV}$ in $600{ }^{\circ} \mathrm{C}$ annealed sample are due to oxygen bonded to hydrogen which are in good agreement with the literature. ${ }^{28}$ These indicate the presence of $\alpha-\mathrm{Fe}_{2} \mathrm{O}_{3}$ and an iron oxyhydroxide in both the samples at different ratios. The ratio between the two peaks corresponding to $\alpha-\mathrm{Fe}_{2} \mathrm{O}_{3}$ and the hydroxide is 22:78 for as-produced sample (Fig. 10a(i)), and 75:25 for the $600{ }^{\circ} \mathrm{C}$ annealed sample (Fig. 10(b)). Therefore, the majority of the as-synthesized product is an oxyhydroxide whereas for the annealed samples, $\alpha-\mathrm{Fe}_{2} \mathrm{O}_{3}$ dominates. The transformation is likely due to the chemical reaction below.

$$
2 \mathrm{FeO}(\mathrm{OH}) \rightarrow \mathrm{Fe}_{2} \mathrm{O}_{3}+\mathrm{H}_{2} \mathrm{O}
$$

Heating the as-produced sample in $\mathrm{UHV}$ at $70{ }^{\circ} \mathrm{C}$ showed only a slight change in the ratio of $\mathrm{O}$ $1 s$ peaks originating from $\alpha-\mathrm{Fe}_{2} \mathrm{O}_{3}$ and $\mathrm{OH}$ with their position remaining the same (Fig. 10 a(ii)). Hence, we can definitely exclude the presence of $\mathrm{OH}$ groups derived from water or surface residual methanol in the sample. However, the $\mathrm{OH}$ peak reduces significantly in the $600{ }^{\circ} \mathrm{C}$ annealed sample compared to that of the $70{ }^{\circ} \mathrm{C}$ annealed in UHV. The positions of the Fe $2 p$ peaks before and after heating in UHV remained the same but the amount of $\mathrm{C}$ in the sample reduced upon heating as expected. Figure 11 shows the high resolution scan of the $\mathrm{C} 1 s$ region and its deconvolution into two peaks, one being attributed to aliphatic $\mathrm{C}-\mathrm{C}$ bonding and the other to the more electronegative $\mathrm{C}-\mathrm{O}$ bonding of the residual organic species from the solvent (methanol). It is found that the peak due to $\mathrm{C}-\mathrm{O}$ bonding reduces enormously due to heat treatment at $70{ }^{\circ} \mathrm{C}$ (Fig. $11(\mathrm{~b})$ ). However, the 
$\mathrm{OH}$ peak in figure 10 does not reduce drastically after this heat treatment.

\section{Ablation with different laser wavelengths}

As the duration of the synthesis affected the morphology and dimensionality of the products during the UV ablation under methanol, we proposed that the growth mechanism must be more complex than just condensation of the ablation products into nanoparticles. Some interaction between the laser and the products in solution appears to be occurring, as the large nanosheets are not observed after 20 mins of laser irradiation. A similar result could be obtained by taking a solution containing mainly nanobelts, and irradiating it with the laser for 10 mins (without the iron powder being present). It was observed that the nanobelts in solution were then converted into nanowires, thus either the nanobelts are being destroyed by the laser, and nanowires are growing in in their place, or the nanobelts are fragmenting into the nanowires.

To test the hypothesis that the laser interaction with the ablation products in solution is important, the ablation synthesis was repeated using longer wavelength $(532 \mathrm{~nm})$ pulses from the second harmonic of a Q-switched Nd:YAG laser delivered at a similar fluence. The resulting solution had a faint yellow coloration. The UV-Vis absorption spectrum of the as synthesized solution is shown as the top curve in figure 12. The absorption coefficient increases rapidly for wavelengths below 400 $\mathrm{nm}$, with a hint of a peak centered at around 300nm. Figure 13(a) shows an SEM image of the material produced using 54,000 $532 \mathrm{~nm}$ laser pulses. Only nanoparticles are observed, even though the laser was run for considerably longer than in experiment that resulted in nanowires for UV ablation. Thus, it is clear that the interaction between the UV photons and the ablation products is required for synthesis of the extended structures. To further demonstrate this, the solution produced with the $532 \mathrm{~nm}$ laser was irradiated for 5 minutes at $20 \mathrm{~Hz}$ and a fluence of $\sim 600 \mathrm{~mJ} / \mathrm{cm}^{2}$ with the $248 \mathrm{~nm}$ excimer laser. When examined in the SEM (see figure 13(a)) the density of nanoparticles was reduced and nanosheets were observed. After a further 10 mins of irradiation, the solution contained mainly small nanowires, as shown in figure 13(c). The optical absorption spectrum of the irradiated solution is shown as the lower curve in figure 12. A clear peak centered at around $325 \mathrm{~nm}$ is observed. This spectrum is very similar to that of the solution produced by UV ablation under methanol. 


\section{Proposed mechanisms for nanostructure growth}

The data presented would support a synthesis mechanism for the extended iron oxide nanostructures (nanosheets and nanowires) by UV ablation with the following steps:

(i) Each laser pulse creates energetic iron species, which react with oxygen or hydroxide ions as they thermalise during collision with the liquid and then rapidly condense into nanoparticles. The source of the oxygen/hydroxide is likely the decomposition of methanol at high temperatures.

(ii) Continued UV laser irradiation of the solution during the ablation continuously evaporates these iron oxide nanoparticles, accompanied by futher oxidation/hydroxidation if possible, producing a constant supply of small iron oxide sub-units in solution.

(ii) Slow (in comparison to the initial condensation) and continuous nucleation of these sub-units onto iron oxide nanoparticles results in the growth of larger nanostructures, which assume the crystal habit of the seed.

Essentially we propose that the synthesis of the extended nanostructures occurs by a selfassembly mechanism, similar to crystal growth, although the final product is largely amorphous in nature. Typically in crystal growth, larger crystallites are only observed when the nucleation density is low and the growth rate is slow. Thus, we suggest that the growth of these extended structures must be a separate mechanism from the rapid condensation typically observed after the ablation event. ${ }^{14}$ As the ablation is continued, the amount of iron oxide sub-units available to grow nanowires increases, thus increasing the nucleation rate and decreasing the size of the nanostructures. This is perhaps why nanowires dominate over the nanosheets after long periods of ablation (see figure 5). The interaction between the nanosheets and the laser may also fragment the nanosheets producing nanowires. Thus, it is likely that the morphology of the products evolves continuously during the synthesis, as the laser constantly destroys larger nanostructures producing more free material to grow new nanostructures. After an extended period of ablation an equilibrium should be reached, when the absorption of the laser in the solution is too large to vaporize additional iron from the powder, then only the continually destruction and regrowth of nanowires will occur.

The final point to discuss, is why the nanowire and nanosheet growth is only seen in methanol and not ethanol or isopropanol. It may be that the decomposition of methanol is more favourable than 
decomposition of the higher alcohols, as complete decomposition of methanol to $\mathrm{CO}$ and $\mathrm{H}_{2}$ does not require any breaking of $\mathrm{C}-\mathrm{C}$ bonds. Also the effect of steric hindrance of the larger molecules may reduce the rate of photocatalytic decomposition of the larger alcohols, ${ }^{29}$ as iron oxide is used as a photocatalyst for the decomposition of methanol to generate hydrogen. ${ }^{30}$ The amount of dissolved water within the different alcohols may also be important as photocatalytic decomposition of water over metal oxide catalysts can be a source of $\mathrm{O} / \mathrm{OH} .{ }^{29}$

\section{Conclusion}

The pulsed laser ablation of iron powder submerged under different liquids was employed as a technique for synthesizing a variety of iron oxides nanostructures. By changing the liquid used it was possible to form hematite nanoparticles in water, or an iron oxyhydroxide nanoaprticles under alcohols. By varying the laser wavelength and the growth time for the pulsed laser ablation of iron under methanol it was possible to grow 0D (nanoparticles), 1D (nanowires) and 2D (nanosheets) of an iron oxyhydroxide that could be readily transformed into hematite by heat treatment in air. We demonstrate that the growth of extended (1D and 2D) nanostructures under methanol is a consequence of a self-assembly mechanism driven by interaction between the laser and the ablation products in the solution, rather than a consequence of rapid quenching of the ablation products immediately after the ablation event.

\section{Methods}

Iron oxide nanostructures are synthesized by a PLA technique using the pulses from a LambdaPhysik LPX 210i excimer laser operating at $248 \mathrm{~nm}$ (UV) with a pulse duration of $25 \mathrm{~ns}$ or a Nd-YAG laser operating at wavelength $532 \mathrm{~nm}$ (green) with duration $15 \mathrm{~ns}$. Iron (Fe) powder (Goodfellow Cambridge Ltd.) with purity $>99 \%$ and maximum particle size of $60 \mu \mathrm{m}$ was used as the starting material and was placed in an open glass vessel mounted on an X-Y translation motorised stage. Sufficient powder was used to make a thin layer $(\sim 5 \mathrm{~mm})$ on the bottom of the vessel, which was then filled with different liquids (water, ethanol, methanol, isopropanol or acetone) up to a depth of $\sim 2 \mathrm{~cm}$. $120 \mathrm{~mJ}$ laser pulses were brought to a focus at the surface of the powder in contact with the liquid, at a fluence of $11 \mathrm{~J} / \mathrm{cm}^{2}$. The laser spot was raster scanned over the 
bottom of the vessel once every $15 \mathrm{~s}$. A laser shot repetition rate of $20 \mathrm{~Hz}$ is used throughout the experiments.

The nanostructure of the products was investigated by in FEI Quanta 200 scanning electron microscope and a Philips CM200 high-resolution transmission electron microscope. The TEM was operated at $200 \mathrm{kV}$ and was also used to obtain the crystal structure of the products by selected area electron diffraction. The crystal structure was also verified by Raman spectroscopy in a Reinshaw Ramanscope. The stoichiometry of the products was determined using X-ray photoemission spectroscopy data from an Omicron Multiprobe ultra high vacuum system equipped with an Omicron EA125 hemispherical analyzer. XPS spectra are acquired with a pass energy of $50 \mathrm{eV}$ for survey and $20 \mathrm{eV}$ for higher resolution respectively, using $\mathrm{Mg} \mathrm{K} \alpha$ radiation from a VG XR3E2 twin anode source. The base pressure was maintained at $\sim 10^{-9}$ mbar for the entire set of experiments. To compensate for possible charging effects, binding energies were normalized with respect to the position of $\mathrm{Au}$ substrate $4 f_{7 / 2}$ line at $84 \mathrm{eV}$. Typically an energy step of $0.1 \mathrm{eV}$ was used for a dwell time of $1 \mathrm{~s}$ and 50 scans are accumulated for each spectrum. Fitting and deconvolution of the spectra were performed with the CASA XPS software employing a Gaussian-Lorentzian line-shape and a Shirley type background.

\section{Acknowledgments}

One of the authors (S.M.) is grateful to Commonwealth Scholarship Commission in the United Kingdom for providing him a fellowship to work in U.K. The authors thank EPSRC for funding in the form of a Portfolio grant and are grateful to Dr. P. May and Dr. J. Smith from the School of Chemistry, University of Bristol for assistance with the Nd:YAG laser ablation experiments. 


\section{References}

1. Kim, C. H.; Chun, H. J.; Kim, D. S.; Kim, S. Y.; Park, J.; Moon, J. Y.; Lee, G.; Yoon, J.; Jo, Y.; Jung, M. H.; Jung, S.; Lee, C. J. Appl. Phys. Lett. 2006, 89, 223103.

2. Fan, Z.; Wen, X.; Yang, S.; Lu, J. G. Appl. Phys. Lett. 2005, 87, 013113.

3. Zhu, Y. W.; Yu, T.; Sow, C. H.; Liu, Y. J.; Wee, A. T. S.; Xu, X. J.; Lim, C. T.; Thong, J. T. L. Appl. Phys. Lett. 2005, 87, 023103.

4. Zhang, Z.; Wei, B. Q.; Ajayan, P. M. Appl. Phys. Lett. 2001, 79, 4207.

5. Fu, Y.; Chen, J.; Zhang, H. Chem. Phys. Lett. 2001, 350, 491.

6. Wen, X.; Wang, S.; Ding, Y.; Wang, Z. L.; Yang, S. J. Phys. Chem. B 2005, 109, 215.

7. Srivastava, H.; Tiwari, P.; Srivastava, A. K.; Nandedkar, R. V. J. Appl. Phys. 2005, 102, 054303.

8. Ashfold, M. N. R.; Claessyens, F.; Fuge, G.; Henley, S. J. Chem. Soc. Rev. 2004, 33, 23.

9. Wood, R. F.; Chen, K. R.; Leboeuf, J. N.; Puretzky, A. A.; Geohegan, D. B. Phys. Rev. Lett. 1997, 79, 1571.

10. Amoruso, S.; Toftmann, B.; Schou, J.; Velotta, R.; Wang, X. Thin Solid Films 2004, 453, 562.

11. Henley, S. J.; Carey, J. D.; Silva, S. R. P.; Fuge, G. M.; Ashfold, M. N. R.; Anglos, D. Phys. Rev. B 2005, 72, 205413.

12. Simakin, A. V.; Voronov, V. V.; Shafeev, G. A.; Brayner, R.; Bozon-Verduraz, F. Chem. Phys. Lett. 2001, 348, 182.

13. Mafuné, F.; Johno, J.; Takeda, Y.; Kondow, T.; Sawabe, H. J. Phys. Chem. B 2000, 104, 8333. 
14. Yang, G. W. Prog. Mater. Sci. 2007, 52, 648.

15. Shangguan, H.; Casperson, L. W.; Prahl, S. A. Appl. Optics 1997, 36, 9034.

16. Pearce, S. R. J.; Henley, S. J.; Claeyssens, F.; May, P. W.; Hallam, K. R.; Smith, J. A. Diamond Relat. Mater. 2004, 13, 661.

17. Sasaki, T.; Shimizu, Y.; Koshizaki, N. J. Photochem. Photobio. A 2006, 182, 335.

18. Bomati-Miguel, O.; Tartaj, P.; Morales, M. P.; Bonville, P.; Golla-Schindler, U.; Zhao, X. Q. Q.; Veintemillas-Verdaguer, S. Small 2006, 2, 1476.

19. Patil, P. P.; Phase, D. M.; Kulkarni, S. A.; Ghaisas, S. V.; Kulkarni, S. K.; Kanetkar, S. M.; Ogale, S. B. Phys. Rev. Lett. 1987, 58, 238.

20. Desai, J. D.; Pathan, H. M.; Min, S. K.; Jung, K. D.; Joo, O. S. Appl. Surf. Sci. 2006, 252, 8039 .

21. Kudasheva, D. S.; Lai, J.; Ulman, A.; Cowman, M. K. J. Inorg. Biochem. 2004, 98, 1757.

22. De Faria, D. L. A.; Silva, S. V.; De Oliveria, M. T. J. Raman. Spectrosc. 1997, 28, 873.

23. Bersani, D.; Lottici, P. P.; Montenero, A. J. Raman. Spectrosc. 1999, 30, 355.

24. Oszko, A.; Kiss, J.; Kiricsi, I. Phys. Chem. Chem. Phys. 1999, 1, 2565.

25. Temesghen, W.; Sherwood, P. M. A. Anal. Bioanal. Chem. 2002, 373, 601.

26. Aronniemi, M.; Sainio, J.; Lahtinen, J. Surf. Sci. 2005, 578, 108.

27. Mills, P.; Sullivan, J. L. J. Phys. D: Appl. Phys. 1983, 16, 723.

28. Walker, J. D.; Tennen Baum, R. Chem. Mater. 2006, 18, 4793.

29. Hameed, A.; Gondal, M. A. J. Mol. Cata. 2005, 233, 35. 
30. Tsoncheva, T.; Rosenholm, J.; Teixeira, C. V.; Dimitrov, M.; Linden, M.; Minchev, C. Microporous and Mesoporous Materials 2006, 89, 209.

31. Xue, D. S.; Gao, C. X.; Liu, Q. F.; Zhang, L. Y. J. Phys. :Condens Matter 2003, 15, 1455. 


\section{Tables}

Table 1: A comparison of previously published methods for the synthesis of iron oxide nanowires with the method discussed here.

\begin{tabular}{|c|c|c|c|c|c|c|c|}
\hline Material & Method & Environment & $\begin{array}{c}\text { Temperature } \\
\left({ }^{\circ} \mathrm{C}\right)\end{array}$ & Time & $\begin{array}{c}\text { Diameter } \\
(\mathrm{nm})\end{array}$ & $\begin{array}{c}\text { Length } \\
(\mu \mathrm{m})\end{array}$ & Ref. \\
\hline $\begin{array}{c}\mathrm{Fe} \\
\text { substrate }\end{array}$ & $\begin{array}{c}\text { Surface } \\
\text { oxidation }\end{array}$ & $\mathrm{O}_{2}$ & 600 & $120 \mathrm{~h}$ & $15-75$ & $10-20$ & $\mathrm{Fu}$ et $a l . .^{5}$ \\
\hline Fe Foil & $\begin{array}{l}\text { Thermal } \\
\text { oxidation }\end{array}$ & $\mathrm{O}_{2}$ & 800 & $10 \mathrm{~h}$ & 40 & $>5$ & Wen et $a l^{6}$ \\
\hline Fe Foil & $\begin{array}{l}\text { Thermal } \\
\text { oxidation }\end{array}$ & Ozone & $400-700$ & $2 \mathrm{~h}$ & 85 & 4 & Srivastava et al. ${ }^{7}$ \\
\hline $\begin{array}{c}\beta-\mathrm{FeO}(\mathrm{OH}) \\
\text { nanowires }\end{array}$ & $\begin{array}{l}\text { Thermal } \\
\text { oxidation }\end{array}$ & Air & 600 & $1.5 \mathrm{~h}$ & 120 & 7 & Xue et al. ${ }^{31}$ \\
\hline $\begin{array}{c}\mathrm{Fe} \\
\text { powder }\end{array}$ & $\begin{array}{c}\text { Laser } \\
\text { Ablation }\end{array}$ & Methanol & $\mathrm{RT}-600$ & $5 \min$ & $20-300$ & $2-8$ & This work \\
\hline
\end{tabular}




\section{Figure Captions}

Figure 1: SEM image of the iron powder used in the experiments

Figure 2: SEM image of the nanoparticles produced by PLA of iron powder under distilled water.

Figure 3: Optical absorption spectrum of the solution produced by UV PLA of iron under distilled water. Inset is a plot of $(\alpha E)^{2}$ versus $\mathrm{E}$ used to estimate the optical band-gap of the product.

Figure 4: Optical absorption spectrum of the solution produced by the UV PLA of iron under (a) ethanol, (b) methanol and (c) isopropanol.

Figure 5: SEM images of the products formed after the UV ablation of iron under methanol with (a) 6000 shots, (b) 9000 shots and (c) 24,000 shots. Inset in (c) is a TEM image of the 24,000 shot sample.

Figure 6: TEM images of the nanowires formed by UV ablation of iron powder. (a) As grown sample. (b) Sample annealed at $400^{\circ} \mathrm{C}$ in air and (c) sample annealed at $800^{\circ} \mathrm{C}$ in air.

Figure 7: SAED pattern of the nanowires after annealing in air at $600^{\circ} \mathrm{C}$. Inset is the SAED pattern for the as produced nanowire sample.

Figure 8: Raman spectra for (a) the unannealed nanowires and samples annealed at (b) $400^{\circ} \mathrm{C}$, (c) $600^{\circ} \mathrm{C}$, and $(\mathrm{d}) 800^{\circ} \mathrm{C}$. Peaks corresponding to hematite ('), the silicon substrate $(\star)$, and a possible peak from the goethite structure (") are labeled. 
Figure 9: Fe $2 p_{3 / 2}$ and Fe $2 p_{1 / 2}$ XPS spectra of (a) the as-produced and (b) $600{ }^{\circ} \mathrm{C}$ annealed nanowire samples produced by UV PLA of iron under methanol.

Figure 10: O $1 s$ XPS spectra of (a)(i) the as-produced nanowire sample (ii) the same sample heated at $70{ }^{\circ} \mathrm{C}$ under ultra high vacuum, (b) is the spectrum the sample heated to $600{ }^{\circ} \mathrm{C}$ in air.

Figure 11: XPS spectra from the $\mathrm{C} 1 s$ region and its deconvolution into two peaks, one being attributed to aliphatic $\mathrm{C}-\mathrm{C}$ bonding and the other to the more electronegative $\mathrm{C}-\mathrm{O}$ bonding of the residual organic species from the solvent (methanol). (a) is from the as-produced nanowire sample and (b) is from same sample heated at $70{ }^{\circ} \mathrm{C}$ under ultra high vacuum.

Figure 12: Optical absorption spectrum of (a) the solution formed by $532 \mathrm{~nm}$ ablation of iron powder under methanol and (b) the same solution after laser annealing with $248 \mathrm{~nm}$ laser pulses.

Figure 13: SEM images of (a) the products formed by $532 \mathrm{~nm}$ ablation of iron powder under methanol, (b) the products after the initial solution was laser annealed for 5 minutes at $20 \mathrm{~Hz}$ and a fluence of $\sim 600 \mathrm{~mJ} / \mathrm{cm}^{2}$ with the $248 \mathrm{~nm}$ excimer laser, and (c) the products after 15 minutes of laser annealing. 


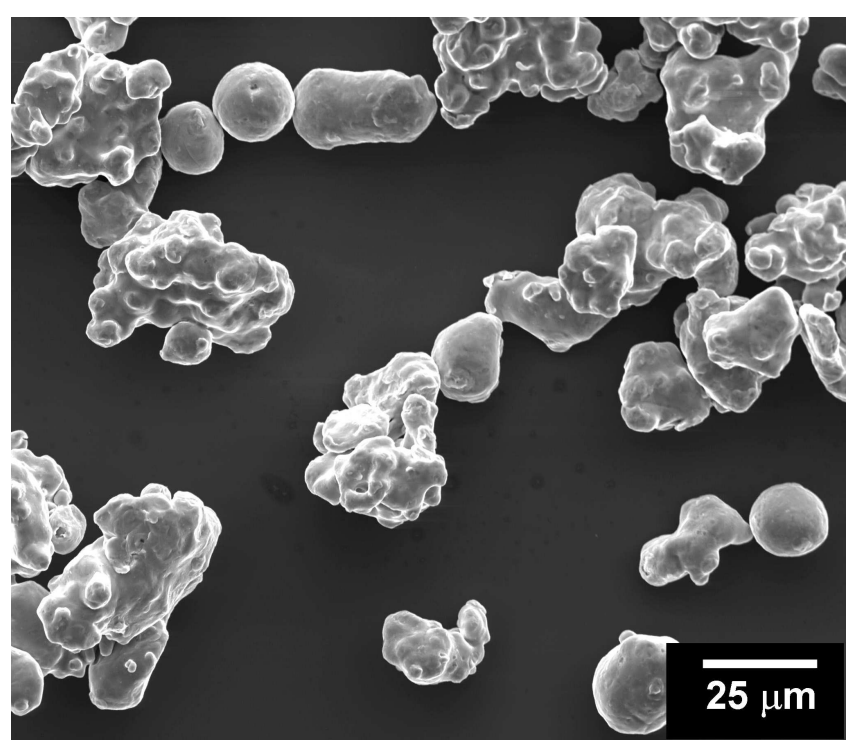

Figure 1. Simon Henley 


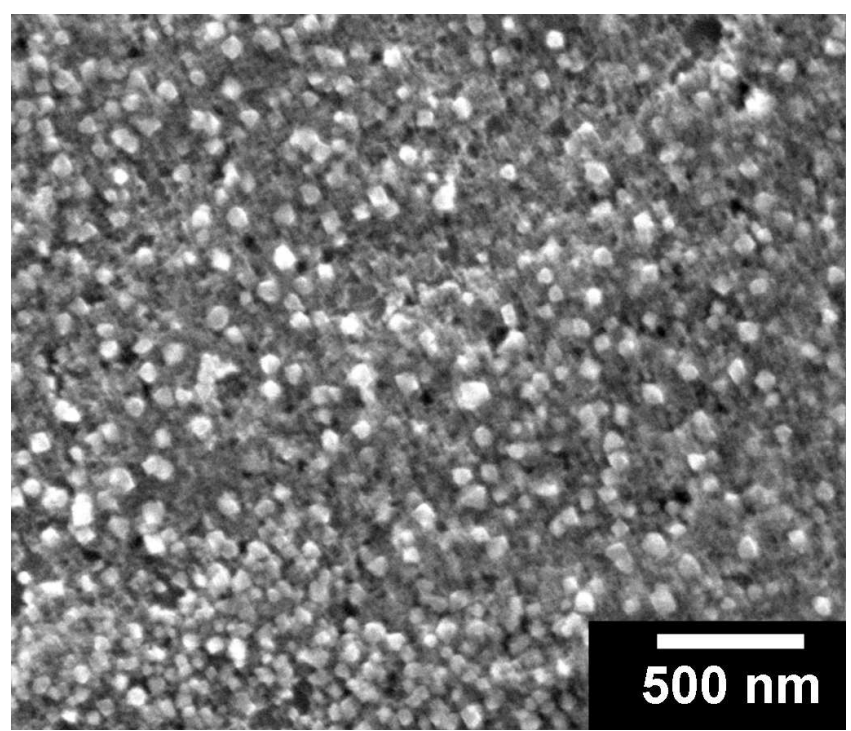

Figure 2. Simon Henley 


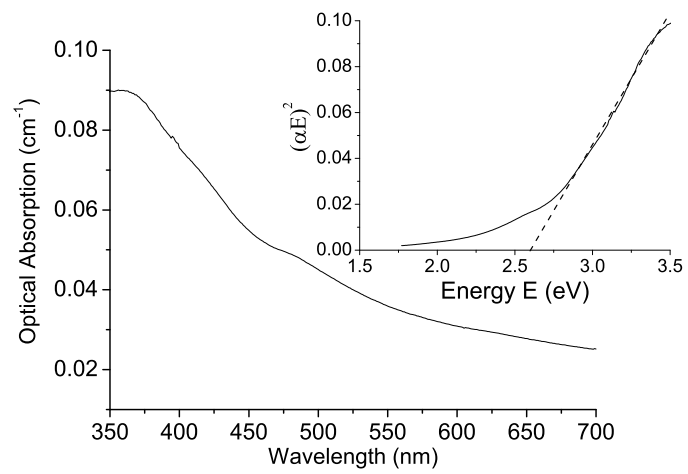

Figure 3. Simon Henley 


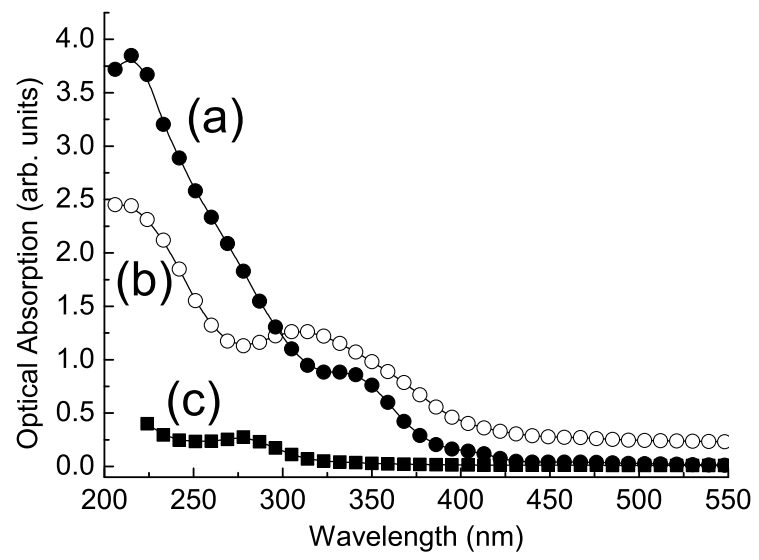

Figure 4. Simon Henley 


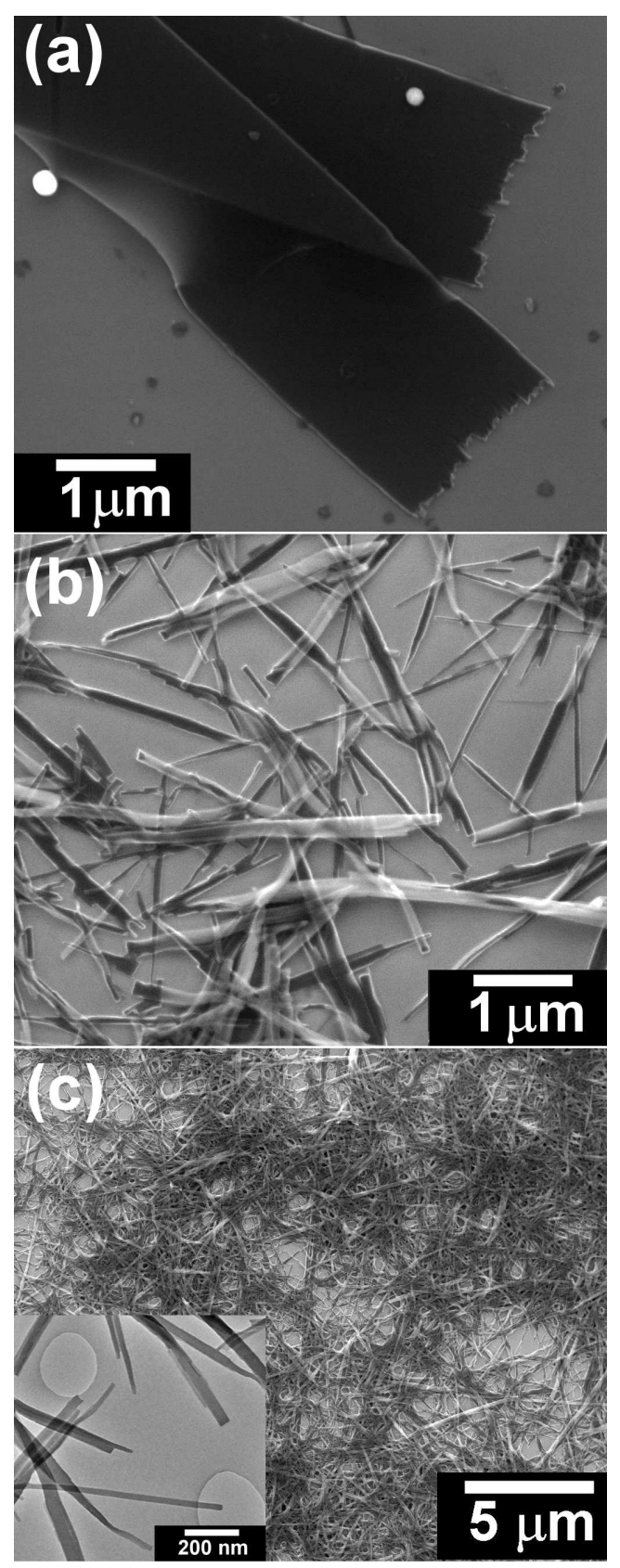

Figure 5. Simon Henley 

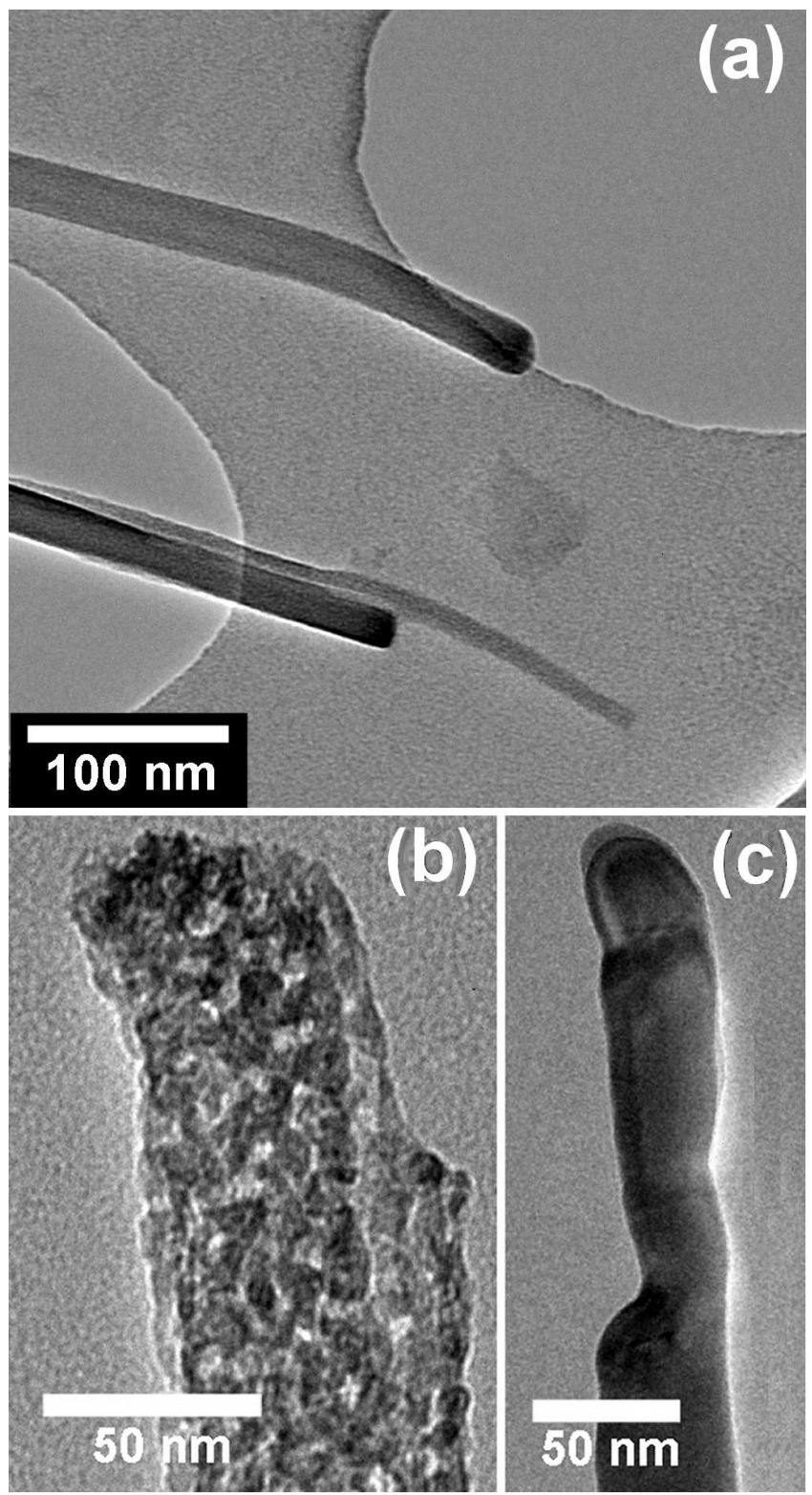

Figure 6. Simon Henley 


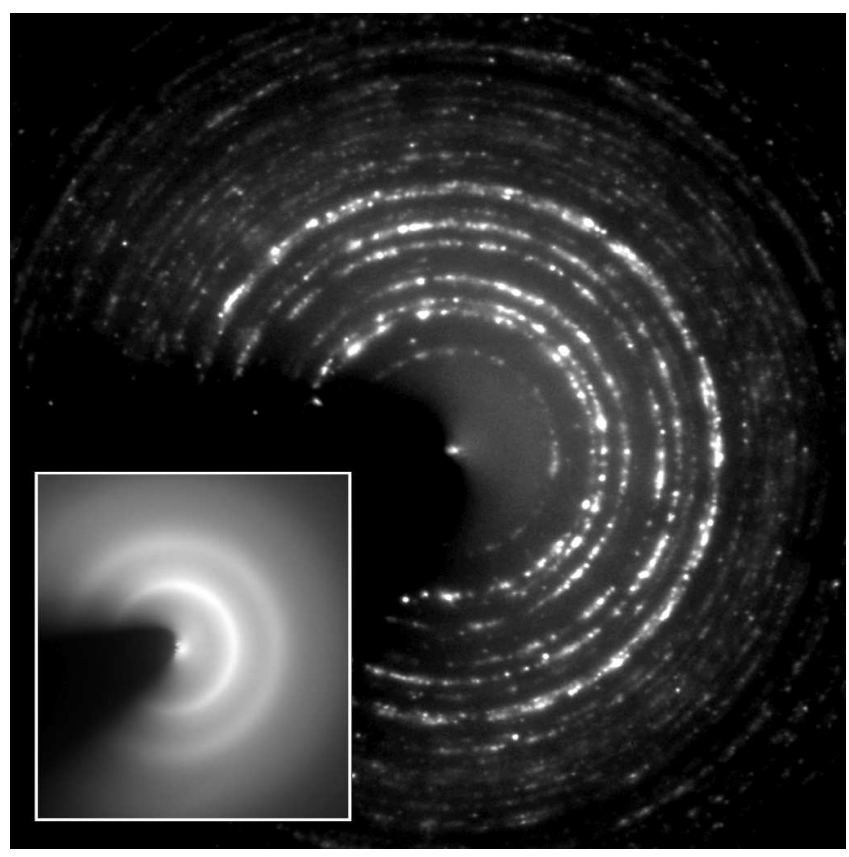

Figure 7. Simon Henley 


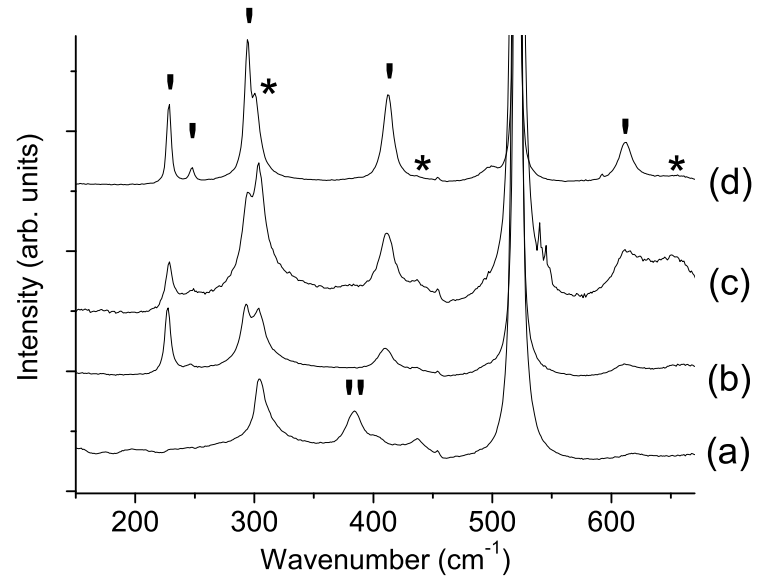

Figure 8. Simon Henley 

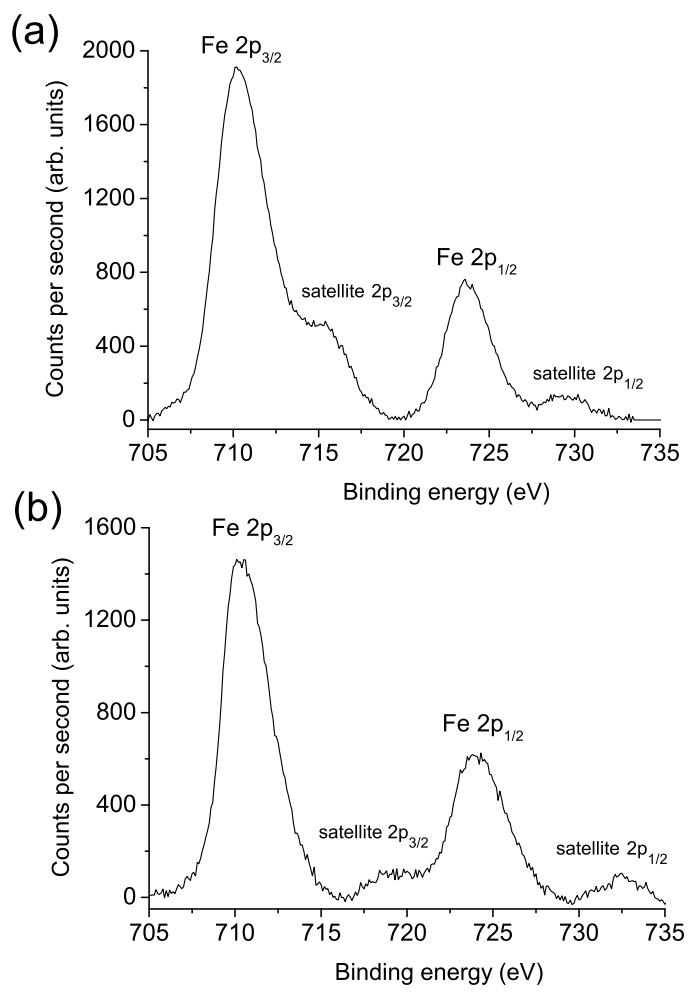

Figure 9. Simon Henley 
(a)

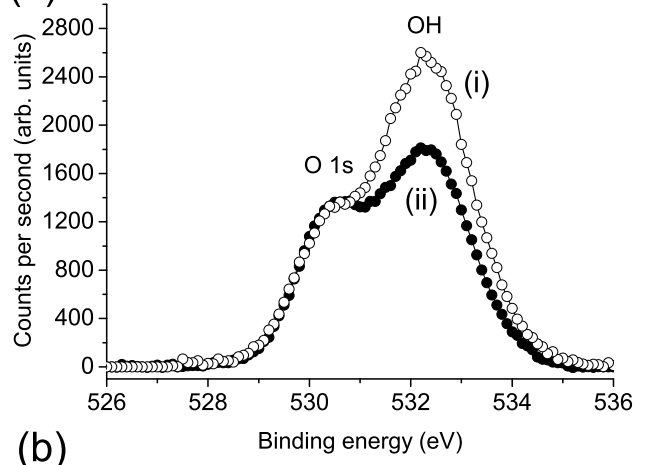

(b)

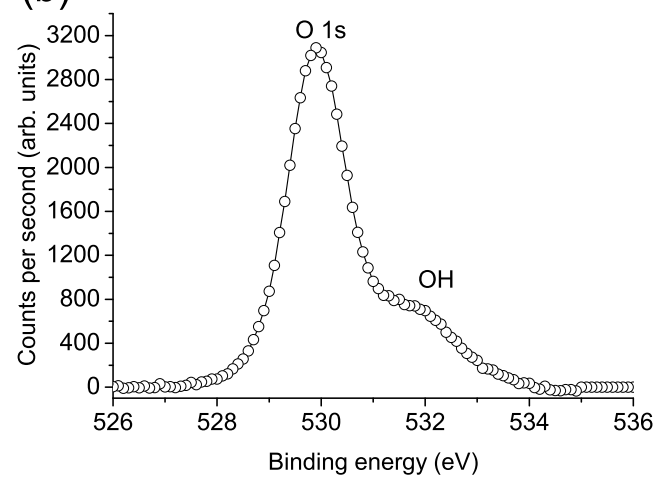

Figure 10. Simon Henley 
(a)

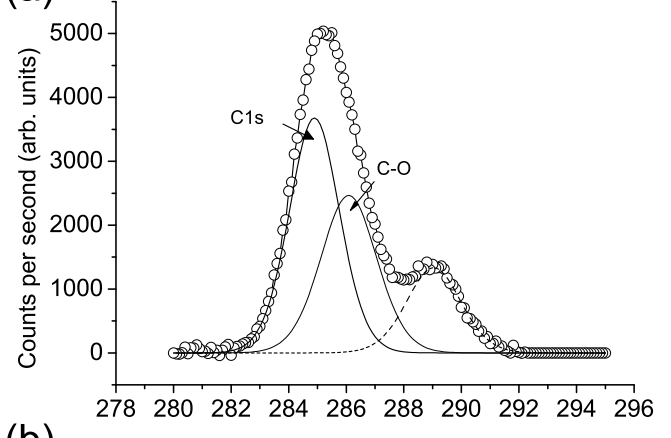

(b)

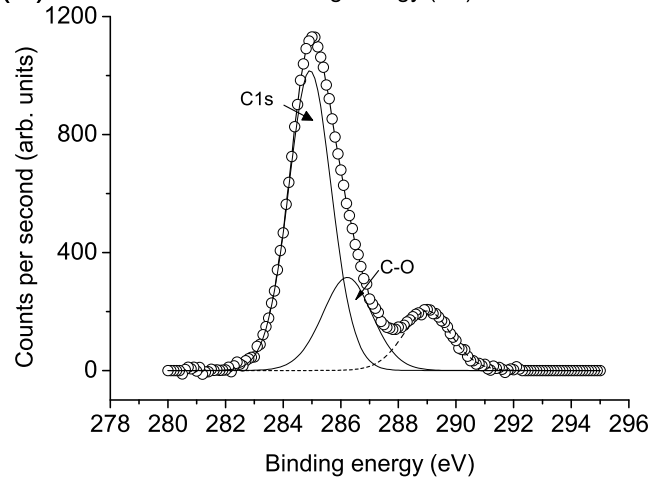

Figure 11. Simon Henley 


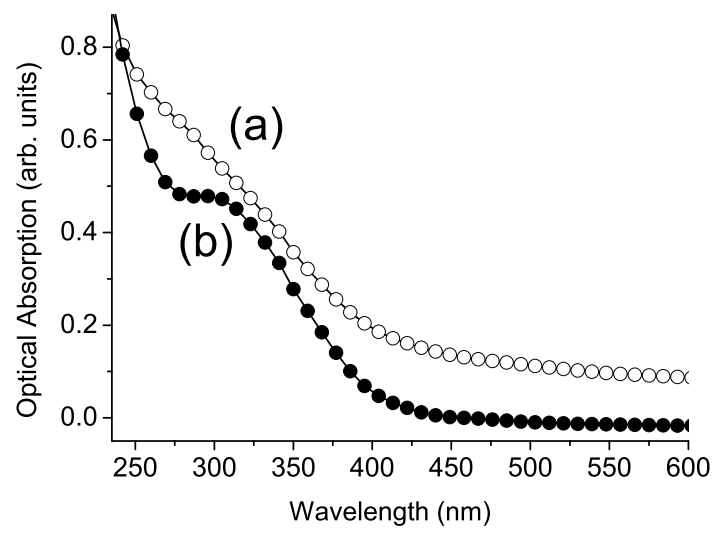

Figure 12. Simon Henley 


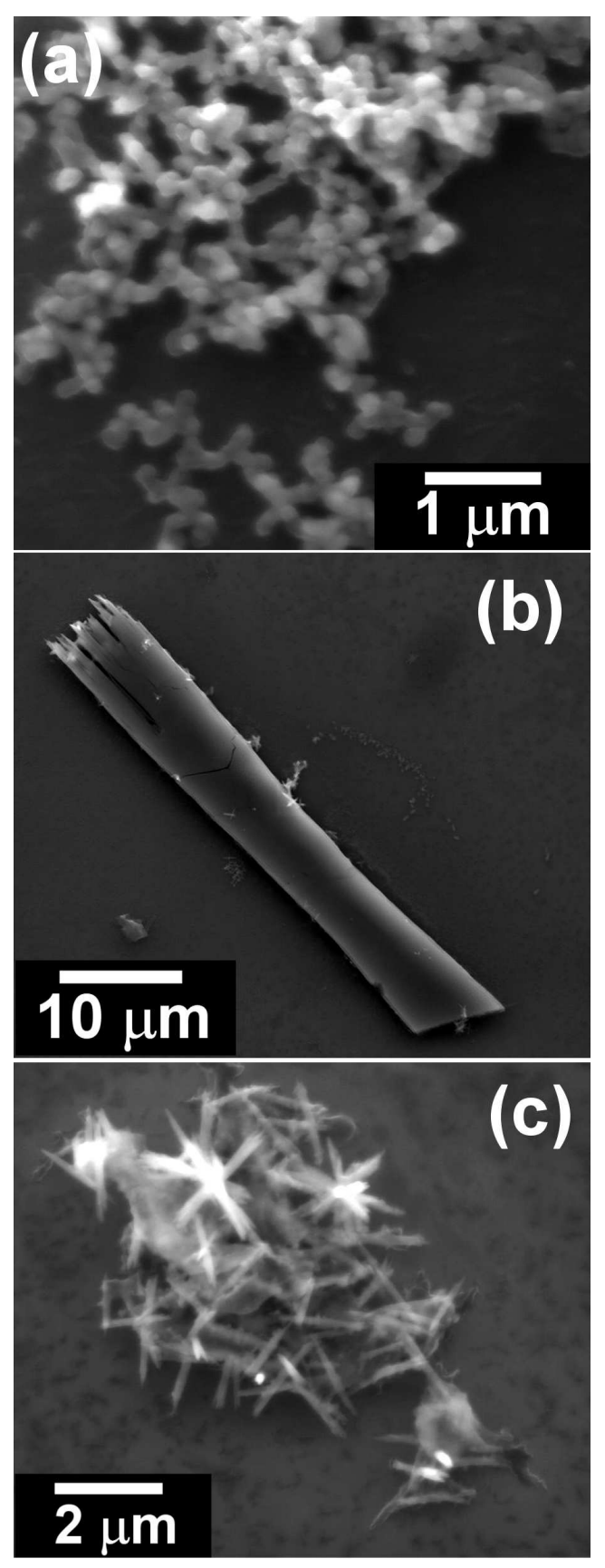

Figure 13. Simon Henley 